\title{
Correlation Between Automated And The Westergren Method For Determination Of ESR
}

Hina Mushtaq, Tariq Mehmood, Imran Khan, Nabila Razvi

ABSTRACT:

Objective: To determine the correlation between automated and the Westergren method for determination of ESR in symptomatic patients.

Study Design and Setting: This cross sectional study conducted at Hematology Department of PNS Shifa Hospital Karachi.

Methodology: Sample size was determined by using WHO sample size calculator. Westergren method was performed according to ICSH's specifications. ESR vacuum tubes containing sodium citrate were used. The sedimentation of the RBC's was recorded visually after 1 hour using a timer. Automated ESR was performed by TEST1 automated ESR analyzer (ALIFAX SpA, Italy). It uses K3-EDTA or K2-EDTA as an anticoagulant. Bias was controlled by inclusion and exclusion criteria and the confounding factors like temperature of lab and effect of wind were controlled by taking appropriate measures. Pre-designed proforma was used to collect the data that was analyzed through SPSS version 16. Correlation between the two methods was measure through Pearson correlation coefficient analysis.

Results: The ESR measured by Westergren method ranged from $2 \mathrm{~mm} / 1^{\text {st }}$ hour. to $131 \mathrm{~mm} / 1^{\text {st }}$ hour, with a mean of $39.94 \pm 29.60 \mathrm{~mm} / 1^{\text {st }}$ hour. while ESR measured by automated method ranged from $2 \mathrm{~mm} / 1^{\text {st }}$ hour. to $120 \mathrm{~mm} / 1^{\text {st }} \mathrm{hr}$. with a mean of $41.67 \pm 32.43 \mathrm{~mm} / 1^{\text {st }}$ hour. There was significantly strong correlation between automated and the Westergren method for determination of ESR $(r=0.945 ; \mathrm{p}=<0.001)$. Similar results were observed across all ages, gender, duration and type of symptoms groups.

Conclusion: Automated and the Westergren method are strongly correlated. Automated method can be used in place of Westergren method for determination of ESR.

Keywords: Automated Method, Erythrocyte Sedimentation Rate, Westergren Method.

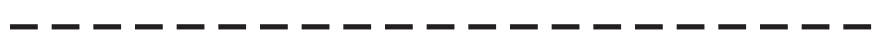

INTRODUCTION:

Erythrocyte sedimentation rate (ESR) is being used to evaluate the prognosis and diagnosis of certain diseases. It indicates the chronic inflammation that may be the pathological process in many ailments ${ }^{1}$.

Although it is non-specific, but this inexpensive test is commonly used in the diagnosis and monitoring of certain disabling conditions including Multiple myeloma, Tuberculosis, Giant cell arteritis, and Rheumatoid arthritis. Moreover, in Hodgkin's disease it is helpful in prediction of relapse. It also has clinical significance in stroke and prognostic value in coronary artery disease $\mathrm{e}^{2,3}$.

The Wetergren method for ESR measurement was first described by Westergren and Fahraeus, henceit is named so. This method is still considered as a reference standardized

Hina Mushtaq,

Department of Haematology PNS Shifa, Karachi.

I Email: heme2018@gmail.com

Tariq Mehmood,

I Department of Medicine PNS Shifa Hospital Karachi

I Imran Khan,

I Department of Medicine PNS Rahat Hospital Karachi.

I Nabila Razvi

I Department of Haematology PNS Shifa, Karachi.

Received: 15-10-18

I Accepted: 13-02-19

JBUMDC 2019; 9(2):109-112 method $^{4}$. According to the recommendation of the International Council for Standardization in Hematology (ICSH) Westergren method is the method of choice for ESR measurement ${ }^{5}$. And subsequently introduced techniques for ESR measurement are being evaluated against this method. But, despite being a standard technique, it has certain disadvantages which limit its application. Therefore newer techniques of automated systems for measuring ESR have been introduced to overcome the disadvantages of the original technique.

In Westergren method the use of citrate, a liquid-based anticoagulant may affect the accuracy of ESR readings. The automated method uses EDTA as an anticoagulant, which is more reliable than the primarily used sodium citrate ${ }^{6,7}$. Other modifications introduced in an automated analyzer include the use of closed blood collection tubes, vacuumcontrolled aspiration of the sample that more reliably provide a correct dilution of sample with the anticoagulant and automated mixing. The automated ESR method helps in avoiding unnecessary exposure of blood samples and therefore reduces the risk to the sample handlers against the blood borne infections such as infectious hepatitis and HIV, This method also minimize the possibility of external influence like temperature, dust particles, positioning of tube and diluents' ratio on the final reading. It also gives the ESR readings in much shorter time.

Studies have been conducted to compare the results of two 
methods but they show difference outcomes. Some concluded that there is agreement between two methods. While other show significant difference between the readings ${ }^{8}$. The available data is still inconclusive therefor this study was aimed to detemine the coorelation between automated and the westergen method for dertermination of ESR in symptomatic patients.

\section{METHODOLOGY:}

This cross-sectional study was conducted at Hematology Department of PNS Shifa Hospital Karachi for ESR evaluation, between Jan 2017 to Nov 2017.

Total 300 blood samples from the patients referred at Hematology Department for evaluation of ESR and fulfilled the inclusion criteria, were selected by Non-Probability, Consecutive Sampling, included in the study. Sample size was calculated according to WHO sample size calculator by applying formula: $n=(u+v)^{2} x(S D \text { of difference })^{2}$ / $(\mu 1-\mu 2)^{2}$

For calculation of sample size, Correlation coefficient was taken as 0.72 with $95 \%$ confidence interval. Further calculation was performed by considering significance level of $5 \%$ and the Power of study $90 \%$ (Beta error $=10 \%$ ). Correlation coefficient, confidence interval, values of Mean and SD were determined after consulting from published study of similar nature.

Both male and female patients of all age groups suffering from more than three days duration of symptoms including: Fever, malaise, cough, muscular, joint pain or generalized weakness associated with above mentioned symptoms were included in the study.

Blood samples taking more than 30 seconds while collection or samples with excessive venous stasis samples without proper proportion to the anticoagulant were excluded from the study. Furthermore, on visual inspection samples with hyperbilirubinemia, Lipemia or hemolysis were also excluded from the study.

Approval was taken from the ethical committee of the hospital to conduct the study. Written consent was taken from each included patient after explaining them the purpose and procedure of the study. $3 \mathrm{ml}$ blood sample was obtained by venipuncture into Tri potassium Ethylene diamine tetra -Acetic acid ( $\mathrm{K}_{3}$-EDTA) vacuum tubes. The samples were thoroughly mixed at the time of venipuncture and also just before analysis. Samples were kept at room temperature and run within the 4-hours period after venipuncture as per ICHS recommendation.

Westergren method performed according to ICSH's specification was considered as standard/reference. Blood was transferred manually from an EDTA tube into ESR vacuum tubes containing sodium citrate. The sedimentation of the RBC's was recorded through visual determination, after 1 hour using a timer.
Automated ESR was performed by TEST1 automated ESR analyzer (ALIFAX SpA, Italy). This analyzer functions on the principle of photometrical capillary stopped flow kinetic analysis. It uses K3-EDTA or K2-EDTA as an anticoagulant.

Bias was controlled by inclusion and exclusion criteria and the confounding factors like temperature of lab, effect of wind were controlled by taking appropriate measures.

Both readings were entered in the proforma along with the demographics and the duration of symptoms. If the patients was already receiving treatment, than it was also documented.

All the collected data was recorded in a proforma specially designed for this study.

All the collected data was analyzed through SPSS version 16. Numerical variables; age, duration of symptoms and ESR value by both the methods have been presented by mean \pm SD. Categorical variables i.e. gender and type of symptoms been presented by frequency and percentage. Pearson correlation coefficient analysis has been used to determine correlation between automated analyzer and Westergren method. Data has been stratified for age, gender, symptoms and duration of symptoms to address effect modifiers. Post stratification Correlation coefficient has been recalculated.

\section{RESULTS:}

The mean age of the patients was $40.58 \pm 20.13$ years. There were $188(62.7 \%)$ male and $112(37.3 \%)$ female patients in the study group. Among the causes for measurement of ESR: Malaise was the most frequent symptom, observed in $249(83.0 \%)$ patients followed by fever $(77.0 \%)$, generalized weakness $(62.3 \%)$, myalgia $(30.0 \%)$, cough $(25.3 \%)$ and arthralgia (15.3\%). The duration of symptoms ranged from 7 days to 21 days with a mean of $13.80 \pm 4.03$ days as shown in Table 1.

The ESR measured by Westergren method ranged from 2 $\mathrm{mm} / 1^{\text {st }}$ hour. to $131 \mathrm{~mm} / 1^{\text {st }}$ hour. With a mean of $39.94 \pm 29.60$ $\mathrm{mm} / 1^{\text {st }}$ hour, while ESR measured by automated method ranged from $2 \mathrm{~mm} / 1^{\text {st }}$ hour. to $120 \mathrm{~mm} / 1^{\text {st }}$ hour. With the mean of $41.67 \pm 32.43 \mathrm{~mm} / 1^{\text {st }}$ hour. There was significantly strong correlation between automated and the Westergren method for determination of ESR $(r=0.945 ; p=<0.001)$ as shown in Table 2. Similar results were observed across all age, gender and type of symptoms groups as shown in Tables 2 and 3 .

\section{DISCUSSION:}

ESR is considered as a poorly understood test and despite the advent of newer techniques, no method certainly ruled out the effects of confounding factors like variations in relative erythrocyte volume or shape ${ }^{9}$. But, despite limitations, it remains a widely used test for the screening and monitoring of various conditions that affect plasma proteins and the sedimentation rate. 
Correlation Between Automated And The Westergren Method For Determination Of ESR

\begin{tabular}{|l|c|}
\hline \multicolumn{1}{|c|}{ Characteristics } & Study Population n=300 \\
\hline Age (years) & $\mathbf{4 0 . 5 8 \pm 2 0 . 1 3}$ \\
\hline Age Groups & $65(21.7 \%)$ \\
\hline$\bullet=25$ years & $147(49.0 \%)$ \\
\hline$\bullet 25-50$ years & $88(29.3 \%)$ \\
\hline$\bullet>50$ years & \\
\hline Gender & $188(62.7 \%)$ \\
\hline$\bullet$ Male & $112(37.3 \%)$ \\
\hline$\bullet$ Female & \\
\hline Symptoms & $249(83.0 \%)$ \\
\hline$\bullet$ Malaise & $231(77.0 \%)$ \\
\hline$\bullet$ Fever & $187(62.3 \%)$ \\
\hline$\bullet$ Generalized Weakness & $90(30.0 \%)$ \\
\hline$\bullet$ Myalgia & $76(25.3 \%)$ \\
\hline$\bullet$ Cough & $46(15.3 \%)$ \\
\hline$\bullet$ Arthralgia & $\mathbf{1 3 . 8 0} \pm \mathbf{4 . 0 3}$ \\
\hline Duration of Symptoms (days) & $19(6.3 \%)$ \\
\hline$\bullet=7$ days & $143(47.7 \%)$ \\
\hline$\bullet$ 7-14 days & $138(46.0 \%)$ \\
\hline$\bullet 14-21$ days & \\
\hline
\end{tabular}

Table 1: Baseline Characteristics of Study Subjects

\begin{tabular}{|c|c|c|c|c|c|}
\hline & $\mathbf{n}$ & Automated & Westergren & Correlation \\
\hline \multicolumn{2}{|c|}{$\mathrm{ESR}(\mathrm{MEAN} \pm \mathrm{SD})$} & 300 & $41.67 \pm 32.43$ & $39.94 \pm 29.60$ & $0.945 * *$ \\
\hline \multirow{3}{*}{ Age } & $<25 \mathrm{yrs}$ & 65 & $30.70 \pm 30.94$ & $29.11 \pm 27.12$ & $0.960 * *$ \\
\hline & $25-50 y r s$ & 147 & $38.05 \pm 29.77$ & $36.63 \pm 28.01$ & $0.950 * *$ \\
\hline & $>50 \mathrm{yrs}$ & 88 & $55.81 \pm 33.29$ & $53.47 \pm 29.37$ & $0.913^{* *}$ \\
\hline \multirow{2}{*}{ Gender } & Male & 188 & $36.48 \pm 32.06$ & $35.42 \pm 30.31$ & $0.952 * *$ \\
\hline & Female & 112 & $50.39 \pm 31.28$ & $47.52 \pm 26.84$ & $0.928 * *$ \\
\hline
\end{tabular}

Table 2: Correlation between Automated and Westergren ESR $\mathrm{P}=<0.001 * *$ Correlation is significant at the 0.01 level (2-tailed).

\begin{tabular}{|c|c|c|c|c|c|}
\hline \multicolumn{2}{|c|}{ Symptom } & \multirow{2}{*}{$\frac{\mathbf{n}}{249}$} & \multirow{2}{*}{$\frac{\text { Automated }}{43.55 \pm 34.11}$} & \multirow{2}{*}{\begin{tabular}{|c|} 
Westergren \\
$41.15 \pm 30.94$ \\
\end{tabular}} & \multirow{2}{*}{\begin{tabular}{|c|} 
Correlation \\
$0.946^{* *}$
\end{tabular}} \\
\hline & Yes & & & & \\
\hline & $\mathrm{No}$ & 51 & $32.53 \pm 20.37$ & $34.00 \pm 21.21$ & $0.944 * *$ \\
\hline \multirow{2}{*}{ Fever } & Yes & 231 & $41.95 \pm 34.12$ & $39.41 \pm 30.85$ & $0.949 * *$ \\
\hline & $\mathrm{No}$ & 69 & $40.75 \pm 26.18$ & $41.70 \pm 25.09$ & $0.933 * *$ \\
\hline \multirow{2}{*}{$\begin{array}{c}\text { Gen. } \\
\text { Weakness }\end{array}$} & Yes & 187 & $47.39 \pm 32.65$ & $45.71 \pm 29.37$ & $0.932 * *$ \\
\hline & $\mathrm{No}$ & 113 & $32.22 \pm 29.87$ & $30.38 \pm 27.56$ & $0.962 * *$ \\
\hline \multirow[b]{2}{*}{ Myalgia } & Yes & 90 & $35.62 \pm 29.51$ & $34.53 \pm 27.68$ & $0.938 * *$ \\
\hline & $\mathrm{No}$ & 210 & $44.27 \pm 33.33$ & $42.25 \pm 30.16$ & $0.947 * *$ \\
\hline \multirow{2}{*}{ Cough } & Yes & 76 & $37.66 \pm 32.72$ & $34.80 \pm 28.00$ & $0.961 * *$ \\
\hline & $\mathrm{No}$ & 224 & $43.04 \pm 32.29$ & $41.68 \pm 29.99$ & $0.941 * *$ \\
\hline \multirow{2}{*}{ Arthralgia } & Yes & 46 & $50.65 \pm 33.53$ & $48.57 \pm 32.39$ & $0.937 * *$ \\
\hline & $\mathrm{No}$ & 254 & $40.05 \pm 32.02$ & $38.37 \pm 28.86$ & $0.946 * *$ \\
\hline
\end{tabular}

Table 3: Correlation between Automated and Westergren ESR across Symptoms

** Correlation is significant at the 0.01 level (2-tailed)
In developed part of the world, the traditional Westergren method is not commonly used in routine laboratories. But, it is considered as the gold standard technique for measuring ESR. Due to various disadvantages, its applications is now limited. To resolve this issue, several techniques to introduce automated systems for measuring ESR have been developed over the last few decades. Some of these involve automation of the Westergren method with diluted or undiluted samples while others use very new technologies. The modification includes the use of undiluted EDTA samples, easier use, closed sample manipulation, conservation of time, vacuumcontrolled aspiration of the sample (which intends to provide a correct dilution with the anticoagulant) and automated mixing.

In the last two decades prevalence of infectious diseases such as Hepatitis B and HIV is increasing, their transmission by blood is a cardinal hazard for medical staff. It is therefore imperative to ensure the safety of laboratory staff against these infectious diseases. Automated techniques offer more benefits in reduction of biohazard.

Another advantage of automated techniques is protection against external influence (temperature, dust particles, position of tube, and diluents' ratio) on the final reading. Moreover, in a specified time the number of evaluated samples is higher with this method than the manual method; a significant advantage in any tertiary care hospital with a heavy workload. But in order to substitute the standard ESR method, these automated instruments must be validated against the standard Westergren method.

In this study significantly strong correlation between automated and the Westergren method for determination of ESR $(r=0.945 ; p=<0.001)$ has been noted. The ESR measured by Westergren method ranged from $2 \mathrm{~mm} / 1^{\text {st }} \mathrm{hr}$. to 131 $\mathrm{mm} / 1^{\text {st }}$ hour with a mean of $39.94 \pm 29.60 \mathrm{~mm} / 1^{\text {st }}$ hour. While ESR measured by automated method ranged from $2 \mathrm{~mm} / 1^{\text {st }}$ hr. to $120 \mathrm{~mm} / 1^{\text {st }}$ hour, with a mean of $41.67 \pm 32.43 \mathrm{~mm} / 1^{\text {st }}$ hour.

In the previously conducted studies, some authors found good correlation and agreement between two methods while few were noted significant discrepancies in the readings of the two methods. Asif et al. (2012) reported significant strong correlation between Westergren and automated methods ( $\mathrm{r}=0.97, \mathrm{p}=0.00$ ) similar to the present study [9]. Drashti in $2016^{10}$, Kamal in $2018^{11}$ and Hashemi et al. in $2014(\mathrm{r}=0.987 ; \mathrm{p}<0.001)^{12}$, Sönmez et al. in 2014 ( $\mathrm{r}=0.978$; $\mathrm{p}<0.05)^{13}$, Cerutti et al. in $2011(\mathrm{r}=0.816, \mathrm{p}<0.05)^{14}$ and Wiwanitkit in $2001(\mathrm{r}=0.98 ; \mathrm{p}<0.05)^{15}$, also observed similar correlation between these two methods. Horsti et al. in 2010 reported relatively lesser correlation $(\mathrm{r}=0.72 ; \mathrm{p}<0.01)$ between these two methods ${ }^{16}$.

Venapusa ${ }^{17}$, in his study determined that automated and Westergren method are correlated at $95 \%$. But, simultaneously he noted higher ESR values with automated method. 
Although, he associated his findings with the presence of systemic bias, but failed to determine its nature. $\mathrm{Al}$ fadhli ${ }^{18}$, observed marked discrepancy in readings between the reference and the automated methods, but mostly with higher ESR readings; While, readings for normal and slightly raised ESR values were about similar by both methods. Similar variations were also noted by Plebani ${ }^{19}$. This study has few limitations: as, it was performed on TEST1 automated ESR analyzer (ALIFAX SpA, Italy), that functions on the principle of photometrical capillary stopped flow kinetic analysis. Therefore, we are unable to comment about validity of other auto analyzers that function on different principles. Furthermore, few samples with very high ESR readings were included so it was difficult to comment on the discrepancies in two methods with higher ESR readings.

It can be thus advocated that automated method is also reliable and can be used for routine estimation of ESR. To determine more reliability on the automated analyzer, further validation experiments and studies, would be required.

\section{CONCLUSION:}

The results of the present study determined the significant correlation between the Westergren method and automated method of ESR estimation.

\section{REFERENCES:}

1. Danesh J, Wheeler JG, Hirschfield GM. C-reactive protein and other circulating markers of inflammation in the prediction of coronary heart disease. N Engl J Med 2004;350(14):138797.

2. Wu LA, Tan SL, Wright RS, Kopecky SL, Burrit MF, Santrach PJ, et al. Prognostic value of the erythrocyte sedimentation rate in patients with unstable angina. Arch Pathol Lab Med 2002;126(7):772.

3. Arikan S, Akalin N. Comparison of the erythrocyte sedimentation rate measured by the Micro Test 1 sedimentation analyzer and the conventional Westergren method'Ann Saudi Med 2007;27(5):362-5.

4. Ozdem S, Akbas HS, Donmez L, Gultekin M. Comparison of TEST 1 with SRS 100 and ICSH reference method for the measurement of the length of sedimentation reaction in blood. Clin Chem Lab Med 2006;44(4):407-12.

5. Atas A, Cakmak A, Soran M, Karazeybek H. Comparative study between the Ves-Matic and Micro erythrocyte sedimentation rate method. J Clin Lab Anal 2008;22(1):702.

6. Ibramanian A, Rangarajan K, Pandey RM, Gandhi JS, Sharma V, Bhoi SK. Evaluation of an mated erythrocyte sedimentation rate analyzer as compared to the Westergren manual method in measurement of erythrocyte sedimentation rate. Indian J Pathol Microbiol 2011;54(1):70-4.
7. Ajubi NE, Bakker AJ, van den Berg G. Determination of the length of sedimentation reaction in blood using the Test 1 system: comparison with the Sedimatic 100 method, turbidimetric fibrinogen levels and the influence of $\mathrm{M}$ proteins. Clin Chem Lab Med 2006;44(7):904-6.

8. Mahlangu JN, Davids M. Three-way comparison of methods for the measurement of the erythrocyte sedimentation rate. J Clin Lab Anal 2008;22(5):346-52.

9. Asif N, Uppal R, Mehmood S, Ahmed A, Ali S, Afzal M. Validation of automated ESR methods with conventional method as gold standard. J Islamabad Med Dent Coll 2012;2(2):81-4.

10. Drashti NS, Shaila NS.comparitive study of Westergren method and Automated ESR analyser(Microsed-10). JMSCR 2016;4(10):13325-29.

11. Kamal P,Vyankatesh TA, Shilpa S.Evaluation of micro ESR method with Westergren methodfor determination of erythyrocyte sedimentation rate. Int J Res Med Sci. 2018; 6(2):628-31

12. Hashemi R, Majidi A, Motamed H, Amini A, Najari F, Tabatabaey A. Erythrocyte Sedimentation Rate Measurement Using as a Rapid Alternative to the Westergren Method. Emerg (Tehran) 2015;3(2):50-3

13. 13Sönmez Ç, Guntas G, Kaymak AÖ, Akkaya N, Akýn KO. Comparison of Erythrocyte Sedimentation Rate Results of Test- 1 and Automatic Westergren Device with Reference Westergren Method. Gazi Med J 2014;25(2):52-4

14. Cerutti H, Muzzi C, Leoncini R, Scapellato C, Cortelazzo A, Furlani E, et al. Erythrocyte sedimentation rate measurement by VES Matic Cube 80 in relation to inflammation plasma proteins. J Clin Lab Anal 2011;25(3):198-202.

15. Wiwanitkit V. Comparative study between the Westergren and automated method for determination of the erythrocyte sedimentation rate.Chiang Mai Med Bull 2001;40(3):139-41.

16. Horsti J, Rontu R, Collings A. Comparison between the StaRRsed Auto-Compact Erythrocyte Sedimentation Rate Instrument and the Westergren Method. J Clin Med Res 2012;2(6):261-5.

17. Vennapusa B, De La Cruz L, Shah H, Michalski V, Zhang QY. Erythrocyte sedimentation rate (esr) measured by the streck esr-auto plus is higher than with the sediplast westergren method. Am J Clin Pathol 2011;135(3);386-90.

18. AlFadhli SM, Al-Awadhi AM. Comparison of erythrocyte sedimentation rate measurement by the automated SEDIsystem and conventional Westergren method using the Bland and Altman statistical method. Med Princ Pract 2005;14(4);2414.

19. Plebani M. Erythrocyte sedimentation rate: innovative techniques for an obsolete test? Clin Chem Lab Med 2003;141(2):115-6. 